\title{
The largest piston diaphragm pump in the world: from drawing board to operational experience
}

\author{
Hein Krimpenfort FELUWA PUMPS, Germany \\ Brad Ricks Brass Engineering, Unites States of America \\ Ernst Schermann FELUWA PUMPS, Germany
}

\section{Abstract}

Over the years, it has become apparent that the demand for high flow rate pipelines, either for concentrate or tailings s/urry, is continuously increasing. At the same time the industry recognized the advantages of piston diaphragm pumps when compared to multistage centrifugal pump installations.

As previously the unit capacity of conventional piston diaphragm pumps was limited, a large number of low capacity piston diaphragm pumps needed to be installed in parallel to meet required high flow rates. This resulted in high costs for purchase of these pumps, as well as high costs for infrastructure around the pumps, such as piping, cabling, booster pumps etc.

For this reason, FELUWA decided to develop a large piston diaphragm pump with a capacity of up to 1000 $\mathrm{m}^{3} / \mathrm{hr}$ (4400 gpm), which increases the unit capacity of such pumps by about $50 \%$. The new pump is of 5 cylinder, single acting configuration and is equipped with double hoses diaphragms, rather than with single flat and circular diaphragms.

A number of these pumps have been installed and the first operational experience has become available. This paper describes the project and application, as well as the background for the development of this type of pump, its most important features, the hydraulic design of the pipeline and operational experience.

In addition, the paper explains in detail why piston diaphragm pumps were selected for this application in favour of centrifugal slurry pumps and how their costs compare.

\section{Introduction}

In 2011, 4 Nos. FELUWA QGK500-5DS350, 5-cylinder single acting piston diaphragm pumps were ordered for the Boleo copper mine in Mexico for the transfer of copper tailings. Although the pumps are designed for a capacity of $1000 \mathrm{~m}^{3} / \mathrm{hr}$, each pump has a capacity of more than $750 \mathrm{~m}^{3} / \mathrm{hr}(3300 \mathrm{gpm})$ at a pressure up to 45 bar (650 psi). The pumps are in operation for 3 years. The hydraulic design of the tailings pipeline was made by BRASS Engineering International from San Ramon, California, USA.

\subsection{Location and history of Minera y Metalurgica de Boleo}

Minera y Metalurgica del Boleo (MMB) is a copper, cobalt, zinc mine which is located near the town of Santa Rosalia in Baja California Sur, Mexico, approximately $850 \mathrm{~km}$ south of San Diego, California, USA.

The property was discovered in the mid 1800s and covers 25 concession covering almost 21000 hectares. Mining began in the 1860 s by Mexican, German and French operators and continued off and on until the 1980s.

In 1992 the property was staked by Baja Mining and subsequently acquired it in 2001, the project is presently 
owned by Minera y Metalurgica del Boleo (MMB), Baja Mining (now Camrova) currently owns $10 \%$ of this company, the remaining 90 is in the hands of a KORES which is a Korean state owned syndicate of industrial companies.

El Boleo is the second largest copper producer and the largest producer of Cobalt in Mexico. Mine life is estimated to be 22 years with a proven reserve of $70 \mathrm{Mt}$.

Construction of the project started in November 2010 and mining operation began in early 2014 after a delay of 2 years which was due to refinancing, restructuring of ownership and political disruptions. Total cost for construction of El Boleo is approximately 2 billion US\$.

The project employs both underground and open-pit mining methods. Approximately $90 \%$ of the material comes from underground operations and the remainder from surface.

The contract for the Engineering, Procurement, Construction and Management was awarded in 2009 to a joint venture between Mexican ICA and Fluor from Dublin, California, USA.

\subsection{Capacity and process description}

Engineering companies Bateman, ICA Fluor, SGS Lakefield and others were responsible for the process design and engineering.

The processing plant is designed to operate at a rate of $3.1 \mathrm{Mt} / \mathrm{yr}$., important to note is that it crushes and mills the ore in seawater. Milling is followed by atmospheric leaching of the whole ore stream at elevated temperatures. This is followed again by atmospheric leaching. Oxidative and a reductive leach are included in the leach circuit to ensure the recovery of oxide and sulphide minerals. From the leach slurry, the metals are separated in a counter current decantation washing circuit.

The annual production capacity of copper is 61000 tons, production of cobalt is estimated to be 2400 tons and zinc around 37000 tons per year.

First copper from the project was produced on 17 January 2015, which would reach a total for that year of 25000 tons, zinc production was 8000 tons and cobalt 600 tons.

In 2008 FLSmith was awarded a contract for the supply of, among others, six 60-meter diameter high-rate thickeners. The slurry produced by the thickeners needs to be pumped through a $60 \mathrm{~m}$ long $500 \mathrm{~mm}$ diameter pipe with a static head of $250 \mathrm{~m}$ to a tailings storage facility situated to the west of the plant site known as the Curuglú area. Minimum transport capacity of the pipeline is 475 dry tons off solids per hour, nominal is 488 and design capacity is 514 tons per hour.

\section{Pump development}

At the same time the Boleo Mine was in the pre-feasibility and feasibility stage, FELUWA management in Germany decided to develop a new type of piston diaphragm pump to meet the ever-increasing demand for high capacity pumps. This resulted in a pump with a maximum capacity of $1000 \mathrm{~m}^{3} / \mathrm{hr}$, which is $50 \%$ higher than of conventional piston diaphragm pumps. At a flow rate of $1000 \mathrm{~m}^{3} / \mathrm{hr}$, the pump is capable of delivering a discharge pressure of 80 bar. At 120 bar discharge pressure, flow rate is still $800 \mathrm{~m}^{3} / \mathrm{hr}$, total absorbed power at full load for this pump is approximately $3000 \mathrm{~kW}$. At past international seminars on paste and thickened tailings, it was presented that such high capacity piston diaphragm pumps can be a feasible alternative for many multistage centrifugal pump systems. The new pump is of different configuration as conventional piston diaphragm pumps.

\subsection{Design philosophy of the 5-cylinder pump}

Large conventional piston diaphragm pumps are usually of 3-cylinder single acting design with a stroke length of $20^{\prime \prime}(504 \mathrm{~mm})$. the flow rate of such pumps is limited to 650 to $700 \mathrm{~m}^{3} / \mathrm{hr}$ which can only be increased by:

- Increasing the stroke rate. 
- The stroke rate of pumps with a stroke length of $20^{\prime \prime}$ is usually limited to 50 per minute, at higher stroke rates the mean piston velocity will become too high which will result in increased NPSHr/risk of cavitation, increased wear of valves and extra vibrations.

- Increasing stroke length.

- An increased stroke length necessitates a decrease in stroke rate for reasons mentioned above, the effect of an increase in stroke length will therefore be nullified by the reduced stroke rate.

- Increasing piston diameter.

- In order to reach a pumping capacity of $1000 \mathrm{~m}^{3} / \mathrm{hr}$ at a maximum of 50 strokes per minute, a diaphragm utilization of $90 \%$ and a volumetric efficiency of $96 \%$, a piston volume of 129 I is required. If a SG of the slurry is considered of 1.7, this means that 50 times per minute a slurry volume of 129 I with a weight of $220 \mathrm{~kg}$ needs to be fed into each diaphragm chamber 50 times per minute. This requires a very high suction pressure. Another consequence is that all pump parts, such as valves and diaphragm chambers will need to increase to impractical sizes. For instance, the diameter of the diaphragm housing will be close to 1 meter. This will make maintenance difficult and potentially dangerous due to the weight and size of these components. Also, valves will need to be very large in size and heavy (> API15).

- As conventional large PD pumps, also the 5-cylinder pump has a $500 \mathrm{~mm}$ stroke length and therefore is allowed to run at 50 strokes maximum continuously. For a flow rate of $1000 \mathrm{~m} / \mathrm{hr}$, under the same conditions as mentioned above the piston volume is therefore only 72 liters. This piston volume is significantly lower than of 3 cylinder pumps ( $129 \mathrm{~L}$ ) and therefore valves can be much smaller, and easier/safer to handle. An additional benefit is the much lower required suction pressure which typically lies in below 2.0 bar.

- Increasing the number of cylinders/diaphragms.

- A last option to achieve a higher capacity of conventional pumps is to increase the number of cylinders and pump heads from 3 to 4 or 5 . Also this option however would lead to significant problems as, due to the fact that the diaphragms of these pumps are circular, the pump would become too wide and the crankshaft too long. As the diaphragm design of FELUWA pumps is tubular rather than circular, this enables the configuration of 5 cylinders in parallel, while maintaining a narrow, relatively small footprint.

\subsection{Additional features of 5-cylinder pumps}

Besides a low NPSHr and small footprint, the 5-cylinder pump offers more remarkable features of which the following are the most significant:

- Pulsations.

- Any PD pump creates pulsations, in a 5-cylinder pumps the peak to peak pulsations are limited to only $7 \%$, whereas the natural peak to peak pulsations of a 3 -cylinder pump are $23 \%$. The pulsations of the 5-cylinder pump are therefore much easier to dampen and require less dampening volume. Also, in case the dampening system does not work properly, $7 \%$ pulsations can be tolerated in the pipeline for a limited period of time, at $23 \%$ undampened pulsations the pump has to shut down immediately.

- Diaphragm design.

- The most remarkable feature of the 5-cylinder pump is its double hose diaphragm: conventional piston diaphragm pumps are equipped with single, flat, circular diaphragms which are prone to fatigue. In case of damage to the diaphragm, pump operation has to be stopped immediately in 
order to avoid contamination of the propelling liquid area and subsequent damage to pistons and cylinder liners.

- The 5-cylinder pump has double, tubular diaphragms which offer redundancy in case of diaphragm damage: as the slurry is contained in the inner diaphragm which is surrounded by an outer diaphragm, pump operation can continue as the leakage of slurry into the propelling liquid chamber is prevented by the secondary diaphragm.

- Valves.

- Most conventional piston diaphragm pumps are equipped with cone type valves which usually consist of more than 6 or 7 different components which are all subject to wear and need to be replaced regularly. Up to a certain maximum flow rate, the 5 -cylinder pump comes with ball valves, benefit of ball valves is there limited number of components: the only wearing parts are the ball, seat and guide. This reduces costs and minimizes downtime, especially when these valves are incorporated in swing out valves which do not necessitate removal of the valve housing from the pump: the valve housing can remain in place and the valve components can be removed from the top of a swung-out valve.

\section{Pump selection sequence at EI Boleo}

\subsection{Tailings pipeline route}

The tailings transfer pipeline goes uphill from approximately $11 \mathrm{~m}$ above sea level while the high points are about 260 m above sea level. Pipeline diameters (DN 450, DN 500, DN 550, and DN 600) were examined based upon the system's capacity requirements, pipe costs, and limiting velocities based upon the slurry properties. It was determined that DN 500 was the most suitable. The pipeline length is approximately $6 \mathrm{~km}$. At 4.7 and $5.2 \mathrm{~km}$ profile high points determine the static lift requirement of $250 \mathrm{~m}$. After the governing high point $(5.2 \mathrm{~km})$ the line runs slack in the steep section until about $5.5 \mathrm{~km}$.

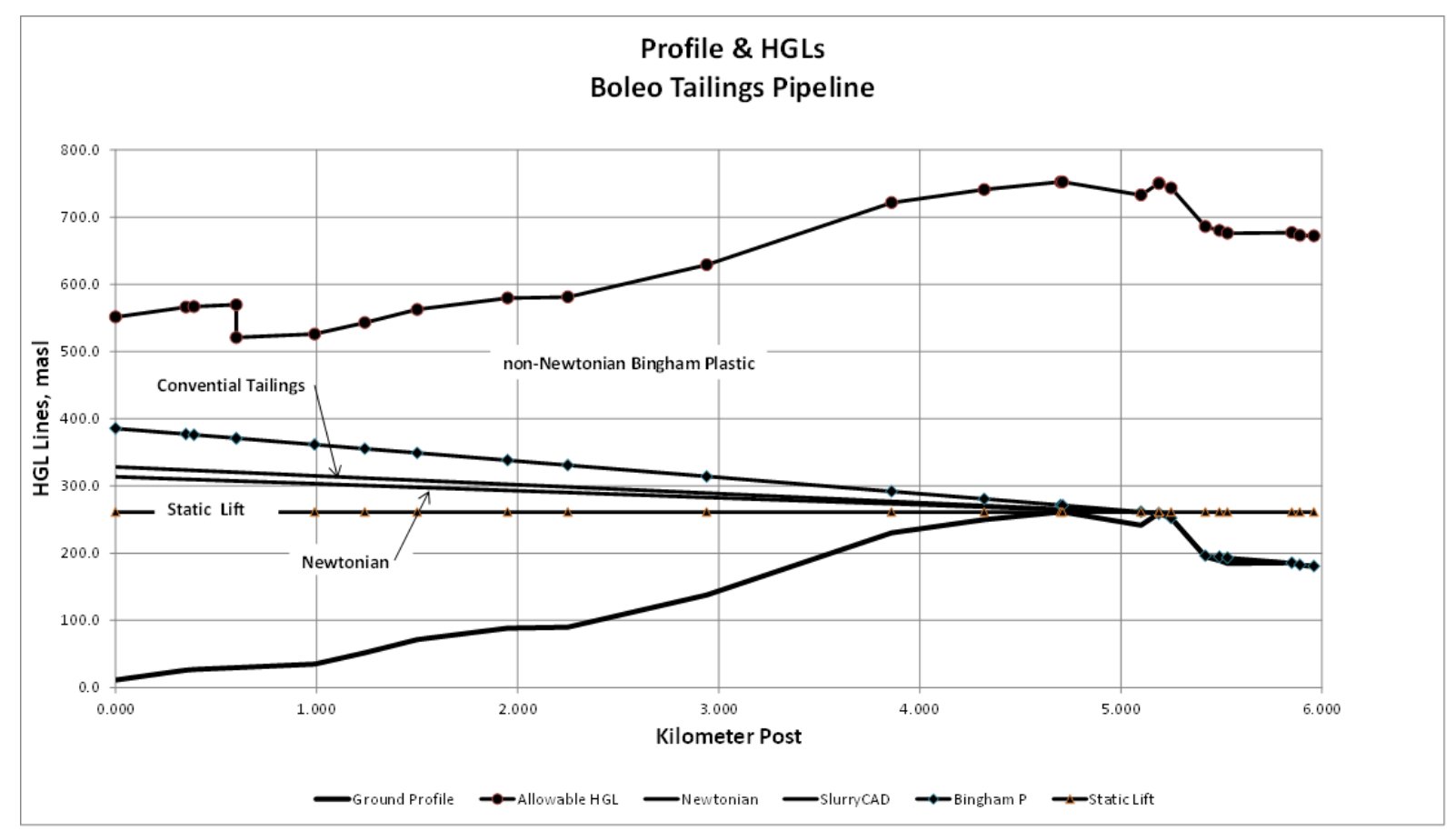

Figure 1 Boleo tailings pipeline route profile 


\subsection{Tailings slurry properties}

The slurry properties are composed of the liquid properties (sea water as the carrier liquid), the solid's properties, and resulting rheological properties of the mixture (water and solids).

The liquid is warm seawater with the following properties:

- Temperature: $36^{\circ} \mathrm{C}$ (warm).

- Liquid SG: 1.06.

- Acidity: $5<=\mathrm{pH}<=6$ (corrosive).

- Viscosity: $0.0008 \mathrm{~Pa} \cdot \mathrm{s}$.

The Boleo Tailings solids are normal:

- Solid's SG: 2.60 (within range of tailings, but less than average).

- Particle size distribution is fine, compared to most tailings with $99.5 \%$ passing 150 microns and $67 \%$ passing 25 microns.

In order to reduce the tailings impoundment's water content, it is specified to operate the system at relatively high concentrations. The system can operate as low as $22 \%$ concentrate by weight $\left(C_{w}\right)$ but the desire is $26 \%$ or more. Because solid's SG less than normal and the PSD significantly finer than normal is an indication that the slurry will have high rheology values. Using a Bingham Plastic rheological model, the expectation is that Boleo's Tailings slurry will have coefficient of rigidity (viscosity) and the yield stress will significantly more than normal tailings slurries. Based upon laboratory results this expectation is confirmed. These high rheological properties will affect the friction losses in the system. Consequently, as the concentration increases the friction demands will correspondingly increase as well. The following section, Section 4 will illustrate how the pumping duties are affected.

\subsection{Pumping duty}

The pumping duty is affected by flows and pressure requirements and also by the corrosive nature of the slurry. Two types of pumps were considered, namely: centrifugal slurry pumps, and positive displacement pumps. Due to the corrosiveness of the slurry, regardless of pump type the wetted parts in contact with the slurry must be corrosion resistant.

\subsubsection{Pump pressures and flows}

Referring to Figure 1 the pipeline profile and hydraulic gradients are shown and illustrate the hydraulic grade line at the pump station. Using this hydraulic grade less the ground elevation at that point determines the head necessary that the pump station must produce to achieve the required flowrate. In the case of Figure 1 it shows the requirements to produce flows sufficient to transport the nominal tonnage.

Because the slurry rheology has a significantly high yield stress a Bingham Plastic friction factor model was used to perform hydraulic analysis for concentrations ranging from 22 to $28 \%$. Table 1 compares Bingham Plastic friction factors against Newtonian friction factors. 
Table 1 Comparing Bingham plastic friction factors against Newtonian friction factors

\begin{tabular}{clll}
\hline \multirow{2}{*}{$\mathrm{C}_{\mathrm{w}}$} & \multicolumn{3}{l}{ Transport tonnage, dry (t/h) } \\
\cline { 2 - 4 } & Minimum & Nominal & Design \\
& 475 & 488 & 514 \\
\cline { 2 - 4 } & \multicolumn{4}{l}{ Friction ratios (BP / Newt) } \\
\hline $22 \%$ & 1.049 & 1.039 & 1.022 \\
$26 \%$ & 2.033 & 1.960 & 1.833 \\
$28 \%$ & 3.523 & 3.367 & 3.069 \\
\hline
\end{tabular}

The above table illustrates the dramatic effect on friction losses as the concentration increases. Because of the incentive to minimize the volume of water in the tailings impoundment, the preferred operation is to transport the tailings in the high end of the concentration range.

\subsubsection{Pump duty for each pump type}

Based upon the hydraulic analysis in the concentration range, and the slurry properties the subsequent pump duties were specified:

Common to both pump types:

- $22.0 \%<=\mathrm{C}_{\mathrm{w}}<=28.0 \%$.

- $1560<=$ Flow $<=1950 \mathrm{~m}^{3} / \mathrm{h}$.

- $330<=\mathrm{tdh}<=440 \mathrm{~m}$.

- $3.85<=$ casing pressure $<=5.25 \mathrm{MPa}$.

Centrifugal pump:

- Medium $<=$ slurry pumping duty $<=$ Heavy.

- $33<=$ tip speed $<=38 \mathrm{~m} / \mathrm{s}$.

- Corrosion resistant lining (High Chrome (28\%) A05) and impeller(High Chrome - G12147A05).

Positive displacement pump (PD pump):

- Corrosion resistant wetted fluid end parts (super duplex steel).

\section{$4 \quad$ Pump station availability}

\subsection{Centrifugal pumps}

Using the pumping duties listed in Section 3.2.1, requests for budget quotes were solicited from centrifugal pump manufacturers. Based upon their replies it was determined that the pump duty fell within the medium to heavy duty slurry pumping. Maximum tip speeds were allowed up to $34.5 \mathrm{~m} / \mathrm{s}$ producing "tdh's" approximately $60 \mathrm{~m}$ necessitating the use of 7+ pumps in series. Consequently, the centrifugal station was configured with 2 pump trains consisting of 8 pumps in series. The statistical availability was calculated for 1 train operating and 1 train as standby. Also, using 3 trains in a 1 operating +2 trains on standby was considered. The calculation considered the seal water pumps for each prime mover. Assuming a prime mover availability of $97 \%$, the $1+1$ 's station availability was determined to be $93.9 \%$ amounting to 535 hours or 22.3 day down time. The same was performed for a 1 train operating +2 trains as standby configuration resulting in an availability of $98.5 \%$ or 132 hours or 5.5 days down time. Summarized:

Availability of $1+1$ centrifugal pump trains:

- $93.9 \%$.

- Down time 535 hours or 22.3 days per year. 
Availability of $1+2$ centrifugal pump trains:

- $98.5 \%$.

- Down time 132 hours or 5.5 days per year.

\subsection{PD pumps}

Using the pumping duties listed in Section 3.2.1, requests for budget quotes were solicited from positive displacement pump manufacturers. Based upon the manufacturer's response two positive displacement pump configurations were considered:

- 3 pumps operating with 1 pump as standby, each capable of $650 \mathrm{~m}^{3} / \mathrm{h}$ at the design pressure.

- 3 pumps operating without standby, each capable of $750 \mathrm{~m}^{3} / \mathrm{h}$ at the design pressure. Normally 3 pumps would operate at $67 \%$ speed (nominal transport) to prolong expendable parts life or 2 pumps operating at $100 \%$ while servicing the other pump. At design flow, 3 pumps operating at $85 \%$ speed.

The availability was calculated for a positive displacement pump station also considering charge pumps in series with 3 pumps operating with 1 pump standby. Assuming 97\% availability for a charge pump and main prime movers the pump station availability was determined to be $99.4 \%$ amounting to 56 hours or 2.3 days' downtime. Considering the nominal transport requirement, a 3-operating pump with no standby configuration determined a $99.2 \%$ availability or 68 hours or 2.9 days' downtime. Summarized:

\section{Availability of $3+1$ PD pumps:}

- $99.4 \%$.

- Down time 56 hours or 2.3 days per year.

\section{Availability of 3 PD pumps (@ nominal capacity):}

- $99.2 \%$.

- Down time 68 hours or 2.9 days per year.

\section{Costs}

Budget cost estimates were compared. For the centrifugal pump station the addition of large positive displacement water pump was added to ensure restart ability of the pipeline should it is shutdown full of settled tailings. Note: quotes from three different PD Pump manufacturers were received. The FELUWA MULTISAFE Double Hose-Diaphragm Pumps were selected based upon limited amount of fluid end parts exposed to the corrosive slurry (valves and seats). Other pumps also utilized corrosion resistant metals, but the quantity of these metals was more than required by the Feluwa pumps and hence more expensive. Consequently, Feluwa pumps were selected for this project.

\subsection{Capex}

For centrifugal pumps, $16(8+8)$ and $24(6+16)$ units were considered, total CAPEX, including VFD's, gland water seal pumps and a back-up PD pump resulted in $\$ 5253000$ (16 pumps) to $\$ 7522000$ for the 24 pumps alternative. For PD pumps, 4 pumps $(3+1)$ were compared with 3 units, total initial investment costs, including VDFD's, charge pumps and seal water systems for these charge pumps are $\$ 8374000$ for 4 pumps and $\$ 7653000$ for 3 PD pumps.

\subsection{Opex}

The operational costs were calculated at an efficiency of $77 \%$ for the centrifugal pumps versus $91 \%$ for the PD pumps. Power price is $\$ 0.088 / \mathrm{kW}$-hr. Regardless of the number of pumps or their configuration $(8+8 / 8$ +16 for centrifugal pumps or $3+1 / 3$ pumps for PD's), the number of operating hours considered ranged 
from 7000 till 8760 and capacities from $1560 \mathrm{~m}^{3} / \mathrm{hr}$ till $1950 \mathrm{~m}^{3} / \mathrm{hr}$. Wear parts costs were calculated to be approximately $25 \%$ of the initial pump investment costs for the centrifugal pumps and $5 \%$ for the PD pumps.

\subsection{Net present value}

Based on an annual discount rate of $6 \%$ and an incremental period of 1 year, the NPV comparison between centrifugal systems and PD system shows pay-back periods from 2.9 to 3.8 years for the PD pumps depending upon the pump station configuration. Over the project life the approximate savings of PD pumps is equal to approximately $\$ 10 \mathrm{M}$ USD.

\subsection{Pump selection summary}

A summary comparing using centrifugal pump against using Feluwa pumps is shown in Table 2 :

Table 2 Pump selection summary

\begin{tabular}{ccc}
\hline Category & Centrifugal pump & 5-cylinder double hose PD pump \\
\hline Slurry dilution & & $\mathrm{X}$ \\
Restart with plug & & $\mathrm{X}$ \\
Corrosion resistance & $\mathrm{X}$ & $\mathrm{X}$ \\
Efficiencies & & $\mathrm{X}$ \\
Availability & & $\mathrm{X}$ \\
Initial costs & $\mathrm{X}$ & \\
NPV analyses & & $\mathrm{X}$ \\
\hline
\end{tabular}

Based upon these comparisons, Feluwa Pumps are recommended.

\section{Operational experience at EI Boleo}

\subsection{Scope of supply}

A total of 4 pumps ( 3 operating +1 standby) were ordered by ICA Fluor from FELUWA. This order was awarded in September of 2011 and the first pump arrived on site in June 2013. The last pump was supplied in 2015.

The scope of supply for the piston diaphragm pumps included pulsation dampening systems, $A B B$ motors and VFD's and Hansen transmission, as well as a contract for a quarterly inspection of the pumps by FELUWA engineers. Centrifugal type charge pumps for the piston diaphragm pumps were supplied by Warman. Figure 2 shows one of the 4 pumps installed at Boleo.

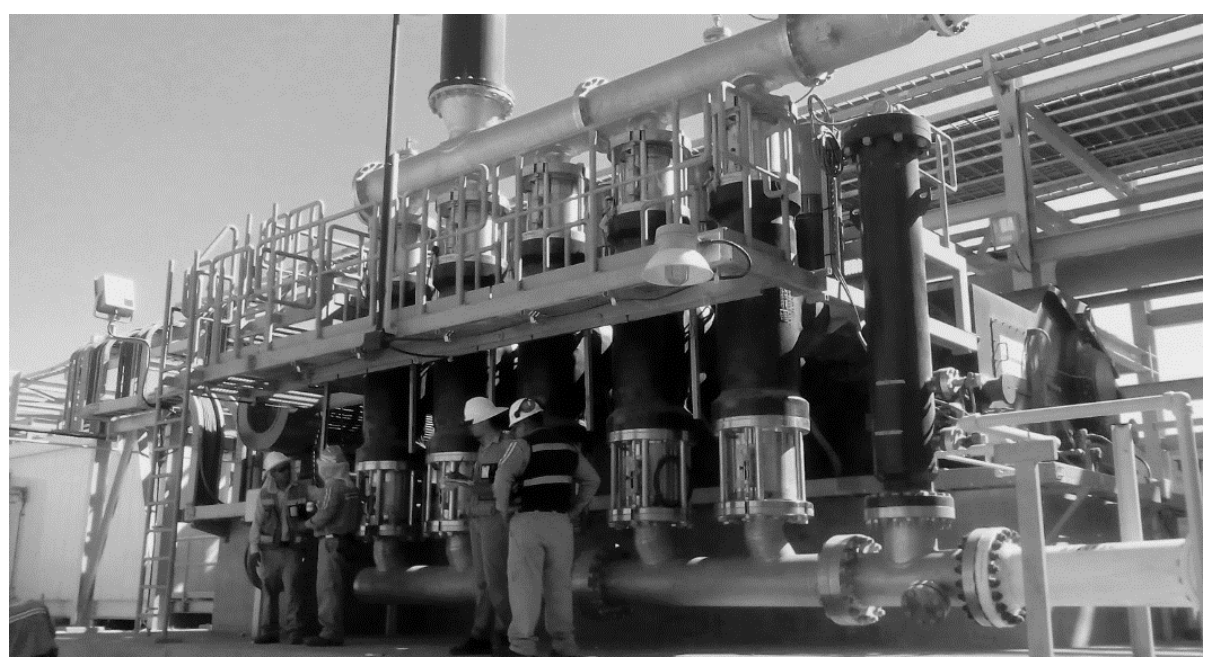

Figure 2 FELUWA QGK500-3DS350 piston diaphragm pump 


\subsection{Material selection}

Due to the fact that the tailings were mixed in sea water, all parts which are in contact with the slurry were manufactured out of duplex stainless steel. This applies to the suction and discharge manifolds, as well as the valves and valve housings. As the slurry is contained in the double hose diaphragms, the diaphragm housings are made of cast iron.

The pumps are of 5-cylinder design and weigh 150 tons each. They are equipped with $380 \mathrm{~mm}$ pistons and run 45 strokes at $750 \mathrm{~m}^{3} / \mathrm{hr}$ capacity. Variable Frequency Drives enable variable flow rates.

The slurry which was available for transfer has never been very consistent: designed was a solids concentration of 25 to $28 \%$, although this concentration was present at times it usually ranged from 20 to $28 \%$. SG of the slurry varied from 1.14 till $1.21 \mathrm{~kg} / \mathrm{L}$.

The pumps are fed by Warman centrifugal charge pumps from a centrally located tank with a storage capacity of $1200 \mathrm{~m}^{3}$.

As the solids concentration in the slurry is relatively low, it can be considered as heterogeneous with a risk of settlement of heavier, large particles at the suction valves which usually are mounted at the down side of the pump. The pumps are therefore equipped with so called Down Flow Technology (DFT) where the slurry flows from the top of the pump to the bottom. The manifold, dampener and suction valves are therefore mounted on top of the pump, whereas the discharge valves, manifold and dampener are at the down side. In such configuration, gravity assists the pump in evacuating heavy particles from the pump and settling of solids within the diaphragm housing will not occur.

Trick in DFT is that the valves have to close upward rather than downward as in conventional up flow technology. They are therefore, in order to save weight, hollow and supported by springs from underneath.

Suction flange is $16 "$ in diameter, the discharge flange has a diameter of $14 "$.

\subsection{Experience}

\subsubsection{Operation}

Operation of the 5 cylinder pumps has been relatively smooth right from the beginning: due to the relatively low weight and small size of valve components and diaphragms and in addition the low pulsations on the suction side of the pump, its NPSHr is only 2 bar which reduces the risk of cavitation. This low pulsation level ensures, trouble free and quiet operation and a long lifetime of foundation, piping, etc.

\subsubsection{Wear part consumption}

As known, due to the fact that the main pumping parts in a piston diaphragm pumps are separated from the slurry by means of a diaphragm, the only parts in such pumps are the diaphragms and valves. After some initial start-up problems in August of 2014, the diaphragms at Boleo currently have a life time of more than 8000 hours. Due to their long-life time, diaphragms are usually not considered as wearing parts.

Valve life has been more problematic: due to the corrosive nature of the slurry, ball material was stainless steel 318i; springs were made of hastelloy C4 and the seat of alloy 2205 super duplex stainless steel.

Initially life time of the spring, balls and seats was limited to a few hundred hours. Also, the manifolds wore out faster than expected.

Main reason for this excessive wear was the corrosiveness of the seawater of which the chloride content was higher than expected. Another reason was that large particles were not filtered from the slurry and went through the pump getting stuck between ball and seat. After trials with several alloy grade combinations, also with non-metallic components, it was concluded that valve balls and seats made of 1.4462 stainless steel was the best combination. Valve life currently is 2 to 3 months of continuous operation (1500 2000 hours), 
depending on solids concentration and maximum particle size in the slurry. The originally thick walled (hollow) balls were replaced for thin walled balls without spring support.

The materials of construction for manifolds was not changed, but retrofitted with a rubber lining.

Flow rate of the pumps depended obviously very much on the availability of slurry. This was not always the case and initially, the pumps ran only at partial load, ranging from 30 to $80 \%$ of design capacity.

As mining and processing operation progress, the throughput of ore becomes more stable and availability of slurry is more constant in quantity as well as consistency.

It may also be of interest to note that the pumps were equipped with electronic crankshaft coupling (also known as "desync" device) which ensures that the pumps do not run synchronous or "in phase". In synchronous mode, the pulsations of the pumps will be added and may result into pulsations in the pipeline of 6 to $9 \%$. The electronic coupling of the pumps prevents synchronous operation which results into peak to peak pulsations in the discharge piping of less than $0.2 \%$.

\subsubsection{Utility consumption}

Due to the reciprocating principle of piston diaphragm pumps, their mechanical efficiency is in excess of $96 \%$, as the hydraulic efficiency is $95 \%$, the total system efficiency is consequently approximately $90 \%$.

The main electric motors of QGK pumps installed at MMB that drive the pump consume $1030 \mathrm{~kW}$ from the grid. The centrifugal pumps that charge the main pump with slurry at a pressure of 2 bar at a capacity of $750 \mathrm{~m}^{3} / \mathrm{hr}$ operate at an efficiency of $75 \%$ and require therefore $55 \mathrm{~kW}$.

Additional power $8 \mathrm{~kW}$ of power is consumed by the built on auxiliary pumps that provide forced lubrication of pump drive and external gearbox. The main pump itself does not require any cooling, only the lubrication system of external Hansen gearbox needs additional, external, cooling provided by a closed loop system water to air cooling system. The fan requires less than $15 \mathrm{~kW}$.

As the diaphragm stroke control system is mechanical, this system does not require any air or power.

Total power consumption of the entire system, per pump, consequently is approximately $1100 \mathrm{~kW}$.

\section{Conclusions}

The 5-cylinder piston diaphragm pump was designed for flow rates of up to $1000 \mathrm{~m}^{3} / \mathrm{hr}$, such capacities cannot be reached with conventional piston diaphragm pumps. For the Boleo copper tailings transfer project, the 5 cylinder, double hose diaphragm pump was compared with conventional PD pumps as well as multistage centrifugal pumps in different configurations. A CAPEX/OPEX comparison favored the installation of PD pumps at the Boleo mine in Mexico where they are in operations since about 3 years. After initial teething problems, which necessitated an adjustment of material selection, the pumps operate satisfactorily at the expected power consumption and wear parts costs. 